\title{
Rat Intestinal Apolipoprotein B Gene Expression

\author{
Evidence for Integrated Regulation by Bile Salt, Fatty Acid, and Phospholipid Flux
}

\author{
Nicholas O. Davidson, "* Michael J. Drewek," Jeffrey I. Gordon," and John Elovson" \\ *Section of Gastroenterology, Department of Medicine, University of Chicago, Chicago, Illinois 60637; ${ }^{*}$ Gastroenterology Unit, \\ Department of Medicine, College of Physicians \& Surgeons, New York, New York 10032; and Departments of Biological Chemistry \\ and Medicine, Washington University, St. Louis, Missouri 63110; "Research Service, Veterans Administration, Wadsworth Medical \\ Center, Los Angeles, California 90073
}

\begin{abstract}
We previously reported that intestinal apo $B_{48}$ synthesis in the rat was unaltered by dietary triglyceride intake but demonstrated regulation in response to biliary lipid availability. Studies are now presented in which the mechanisms underlying biliary lipid dependent expression of intestinal apo $B_{43}$ synthesis have been investigated further. Bile salt replacement was effective in a dose- and structure-dependent manner in reexpressing intestinal apo $B_{48}$ synthesis after prolonged bile diversion. Further experiments suggested that this effect of bile salt may be related to facilitated uptake of fatty acid. A role for mucosal phospholipid flux was suggested by studies in which infusion of lysolecithin, with or without $\mathrm{Na}$ taurocholate, produced complete reexpression of apo $B_{48}$ synthesis in jejunal enterocytes. Over a four- to sixfold range of apo $B_{48}$ synthesis rates in both jejunum and ileum, there was no change in apo $B$ mRNA size or abundance as determined by RNA blot hybridization. Analysis of both intestinal mucosa and microsome lipid content in a variety of settings revealed that apo $B_{48}$ synthesis rates were correlated with microsome triglyceride fatty acid content $(r=0.65, P<0.005)$ but not free fatty acid or phospholipid content. These studies demonstrate a physiologic role for elements of biliary lipid flux in the regulation of apo B gene expression. The data suggest that an integrated mechanism may exist whereby apo $B_{48}$ synthesis is related to microsome triglyceride flux, particularly at low levels of lumenal substrate availability.
\end{abstract}

\section{Introduction}

Apolipoprotein (apo) B is a large, hydrophobic protein synthesized in mammalian liver and intestine. Although details of its intracellular assembly and lipid association are unclear, apo B is an integral component of triglyceride-rich lipoproteins (chylomicrons and VLDL) and LDL (reviewed in reference 1). Two major species exist in humans: apo $B_{100}\left(M_{\mathrm{r}} \sim 500 \mathrm{kD}\right)$,

Address reprint requests to Dr. Davidson, University of Chicago, Department of Medicine, Gastroenterology Section, Box 400, 5841 South Maryland Avenue, Chicago, IL 60637.

Presented in part at the 58th American Heart Association Meetings, November 1985, and published in 1985. (Circulation. 72: III: 286.)

Received for publication 6 October 1986 and in revised form 3 February 1988.

J. Clin. Invest.

(c) The American Society for Clinical Investigation, Inc.

0021-9738/88/07/0300/09 \$2.00

Volume 82, July 1988, 300-308 which is synthesized in the liver and is the principal protein constituent of $\mathrm{LDL}$, and apo $\mathrm{B}_{48}\left(M_{\mathrm{r}} \sim 230 \mathrm{kD}\right)$, which is synthesized by small intestinal mucosa and secreted as a component of chylomicrons and VLDL (2). Unlike the situation in humans, both molecular forms of apo B are synthesized and secreted by rat hepatocytes (3). Rat enterocytes, by contrast, synthesize and contain only apo $\mathrm{B}_{\mathbf{4 8}}(4,5)$.

Over the last two years a number of groups have isolated complementary DNA (cDNA) clones encoding different regions of both rat and human apo $B_{100}(6-12)$. A dominant $\sim 15 \mathrm{~kb}$ mRNA species has been identified in both intestine and liver using CDNA probes encoding either amino- or carboxyl-terminal domains $(8,10,12,13)$. Recently, independent studies by Powell et al. (13) and Chen et al. (14) indicate that apo $\mathrm{B}_{48}$ in human and rabbit intestine represents the $\mathrm{NH}_{2}$ terminal 2152 amino acids of apo $\mathrm{B}_{100}$ and arises by a novel coor posttranscriptional nucleotide modification that produces a stop codon in apo $B_{100}$ mRNA.

There is little direct information about the mechanism(s) of regulation of apo B gene expression. Evidence based on a number of well characterized human genetic syndromes suggests that apo $B_{100}$ and apo $B_{48}$ may be independently and somewhat variably expressed in liver and intestine of human subjects (15-17). These rare genetic syndromes are accompanied by varying degrees of failure of secretion of triglyceriderich lipoproteins from enterocytes and hepatocytes (15-17), suggesting that apo B gene expression may be critical to the process of assembly and secretion of these lipoprotein classes. Additionally, developmental changes have been described in the ratios of apo $B_{100}$ and apo $B_{48}$ synthesized by human fetal small intestine (18) and in a number of embryonic and developing rat tissues (19). The relative roles played by dietary and hormonal factors in regulating apo $B$ gene expression have as yet been poorly defined. We recently demonstrated that rat intestinal apo $\mathbf{B}_{48}$ synthesis was not regulated by acute triglyceride flux, but appeared to be sensitive to aspects of biliary lipid flux (4). We now report studies that further characterize the regulation of intestinal apo $B$ gene expression by different elements of biliary lipid flux.

\section{Methods}

Animals and surgical protocol. Male Sprague-Dawley rats (150-200 g) were obtained from Charles River Breeding Laboratories, Wilmington, DE. All animals had free access to water and standard pelleted rat chow (Ralston-Purina, St. Louis, MO) until the day of surgery.

External bile diversion was performed as described (4) using polyethylene tubing to cannulate both duodenum (PE-90) and distal common bile duct (PE-50). All animals (except controls, see below) underwent external bile diversion and received an intraduodenal infusion of $10 \%$ dextrose- $0.9 \% \mathrm{NaCl}-0.04 \% \mathrm{KCl}$ (D10-saline) at a rate of $2.4 \mathrm{ml} / \mathrm{h}$ 
for 26-30 h. This time point has been previously demonstrated (4) to produce a nadir of jejunal apo $B_{48}$ synthesis following external bile diversion. The duodenal infusate was changed, according to the experimental protocols detailed below, so that animals received the specific test infusate at $2.4 \mathrm{ml} / \mathrm{h}$ for the last $16-18 \mathrm{~h}$ of bile diversion. The total

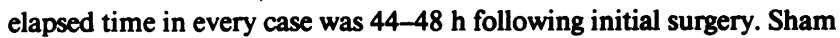
operated controls underwent laparotomy and exposure but not cannulation of the bile duct. These animals were similarly restrained and infused with D10-saline for $48 \mathrm{~h}$.

Determination of intestinal apo $B_{48}$ synthesis rate. After the respective manipulations (detailed in the legends to figures) animals were anesthetized with sodium pentobarbital and $10 \mathrm{~cm}$ loops of jejunum (proximal portion $5 \mathrm{~cm}$ from ligament of Treitz) and ileum (distal portion $5 \mathrm{~cm}$ proximal to ileocecal valve) were pulse-labeled with L-[4,5- $\left.{ }^{3} \mathrm{H}\right]$ leucine (> $120 \mathrm{Ci} / \mathrm{mmol}$; Amersham Corp., Arlington Heights, IL) for $9 \mathrm{~min}$. This time point effectively precludes any apparent hepatic contribution to newly synthesized intestinal apo $B_{48}(4)$. After exsanguination, the loops were removed and enterocytes isolated using citrate-EDTA chelation (4). Enterocyte isolation buffers contained, sequentially 20,10 , and $5 \mathrm{mM}$ leucine as detailed (4) to prevent isotope reutilization. The final cell pellet was homogenized on ice in PBS-1\% Triton-2 mM leucine-1 mM PMSF-1 mM benzamidine, $\mathrm{pH}$ 7.4 , and a $105,000 \mathrm{~g}$ supernatant prepared. These conditions have been previously shown to optimize apo B recovery from intestinal cells (4). Aliquots of homogenate were saved for measurement of total protein concentration (20) and TCA-insoluble radioactivity. Aliquots of cytosolic supernatant were reacted with excess apo B antiserum and the immune complex precipitated by addition of washed Staphylococcus aureus cells. After extensive washing, the immune complex was characterized by SDS-PAGE and radioactivity incorporated into apo $\mathbf{B}_{48}$ determined by liquid scintillation spectrometry. Characterization of antiserum specificity and parameters for determining antiserum excess stoichiometry have been previously provided (4).

Apo $B_{48}$ synthesis rates are expressed as a fraction of total protein synthesis (4). Each value represents the mean of two to four separate assays corrected for nonspecific and background radioactivity. Quantitation of apo $B_{48}$ synthesis as a relative rate assumes that the proportion of leucine residues represented in the apo B peptide remains constant and that leucine uptake and incorporation into total cellular protein is comparable between the different treatment groups. Incorporation of $\left[{ }^{3} \mathrm{H}\right]$ leucine into cellular protein was compared among 15 experimental groups reported below ( $n=68$ for jejunum, $n=61$ for ileum). Comparisons were made to simultaneously studied animals with bile fistula alone and sham-operated controls, both groups being infused with D10-saline for $48 \mathrm{~h}$. Animals receiving $5 \mathrm{mM} \mathrm{Na}$ tauroursodeoxycholic acid (NaTUDCA) ${ }^{1}$ were noted to have higher incorporation of $\left[{ }^{3} \mathrm{H}\right]$ leucine into cellular protein in ileal enterocytes $(2.76 \pm 0.74 \mathrm{cpm} / \mathrm{ng}, n=5)$ than either bile diverted animals $(1.76 \pm 0.67 \mathrm{cpm} / \mathrm{ng}, n=8, P=0.046)$ or sham-operated controls $(1.06 \pm 0.033 \mathrm{cpm} / \mathrm{ng}, n=3, P=0.0053)$. This treatment group aside, there were no differences in the incorporation of $\left[{ }^{3} \mathrm{H}\right]$ leucine into cellular protein among the groups studied when compared to both matched control groups cited above (data not shown). Thus, the changes reported in apo $B_{48}$ synthesis rates (below) reflect a real change in apolipoprotein synthesis rate and not an apparent difference in the face of altered total cellular protein synthesis.

RNA extraction and analysis. Total cellular RNA was extracted from the proximal (jejunum) and distal (ileum) one-third of the small intestine using $8 \mathrm{M}$ guanidine- $\mathrm{HCl}$ as described by Gordon et al. (21). Yields of total cellular RNA averaged 3-6 mg/g wet weight mucosa. Hepatic RNA was similarly extracted, with comparable yield. All preparations of RNA were determined to be intact following analytical

1. Abbreviations used in this paper: CMC, critical micellar concentration; FA, fatty acid; PC, phosphatidylcholine; SSC, $0.15 \mathrm{M} \mathrm{NaCl} / 0.015$ M Na citrate, pH 7; TG, triglyceride; NaTUDCA, Na tauroursodeoxycholic acid. methylmercury agarose gel electrophoresis (22), (data not shown). Isolation of total cellular RNA using guanidine isothiocyanate- $\mathrm{CsCl}_{2}$ centrifugation (23) resulted in lower yields but similar patterns of apo B mRNA following Northern transfer (see below).

For quantitation of apo B mRNA abundance serially diluted aliquots of total cellular RNA (0.5-3.0 $\mu \mathrm{g})$ were applied to nitrocellulose filters using a commercial template as previously described (19). In addition, samples of intestinal and hepatic total cellular RNA (30 ng-3 $\mu \mathrm{g})$ were run as internal standards for each filter. Filters were probed with a 2.9-kb cDNA to rat apo $B_{100}$ (19) labeled with ${ }^{32} \mathrm{P}$ to a specific activity of $10^{8}-10^{9} \mathrm{cpm} / \mu \mathrm{g}$ (24). Hybridization solutions ( $\mathrm{pH} \mathrm{7.0)}$ contained $50 \%$ (vol/vol) formamide, $6 \times$ standard saline citrate (SSC), $50 \mathrm{mM}$ sodium phosphate, $1 \mathrm{mM}$ EDTA, $1 \times$ Denhardt's solution, 50 $\mu \mathrm{g} / \mathrm{ml}$ sheared, single-stranded salmon sperm DNA, and $10 \%$ (wt/vol) dextran sulfate. Following a $24-\mathrm{h}$ incubation at $42^{\circ} \mathrm{C}$, filters were washed twice in $0.1 \%$ (wt/vol) SDS $/ 1 \times \mathrm{SSC}$ at $25^{\circ} \mathrm{C}$ and four times $(15$ min each) in $0.1 \times \mathrm{SSC}$ at $50^{\circ} \mathrm{C}$ before autoradiography. Apo B mRNA abundance was calculated by quantitative scanning densitometry using a laser densitometer (Ultroscan LX, LKB Instruments, Inc., Gaithersburg, MD). Relative abundance was calculated by reference to a standard curve constructed from the signals of hepatic and intestinal RNA standards, thereby allowing comparison between different films. Only signals in the linear range of film sensitivity were used (19).

Northern blots of total intestinal and hepatic RNA were prepared as described (25) following fractionation through $6 \%$ formaldehyde/ $0.75 \%$ agarose gels. These blots were hybridized as described above with both the apo B cDNA and subsequently with a Bal/Pst I restriction fragment of pAIV303 DNA that encodes 1250 nucleotides of rat apo AIV mRNA (26). Northern blots were also hybridized to a cDNA for rat fibronectin ( $\lambda$ RLF-1 from Dr. R. Hynes, Massachusetts Institute of Technology, Boston, MA) as described (27).

Intestinal microsome preparation and lipid analysis. After exsanguination, the intestine was removed, incised longitudinally and the mucosa flushed extensively with ice-cold $0.9 \% \mathrm{NaCl}-2 \%$ Triton as described (28). The mucosa was then scraped and portions homogenized directly (Polytron setting 5 for $30 \mathrm{~s}$ ) in $0.9 \% \mathrm{NaCl}-5 \mathrm{mM}$ EDTA. These homogenates were frozen at $-80^{\circ} \mathrm{C}$ until used for lipid extraction. Other portions were suspended in 5 vol of medium I $(0.25 \mathrm{M}$ sucrose$10 \mathrm{mM}$ Tris-1 mM EDTA, pH 7.4) and homogenized on ice by 8-10 strokes of a loose fitting Teflon-glass homogenizer. The homogenate was centrifuged at $2,000 \mathrm{~g}$ for $10 \mathrm{~min}$ and the resulting supernatant centrifuged at $25,000 \mathrm{~g}$ for $10 \mathrm{~min}$, both at $4^{\circ} \mathrm{C}$. This supernatant was centrifuged at $100,000 \mathrm{~g}$ for $60 \mathrm{~min}$ at $4^{\circ}$ and the pellet suspended in 1 $\mathrm{ml} 0.5 \mathrm{M} \mathrm{KCl}-0.25 \mathrm{M}$ sucrose. After centrifugation at $100,000 \mathrm{~g}$ the final, washed microsome pellet was resuspended in $2 \mathrm{ml}$ medium I, aliquoted, and frozen at $-80^{\circ} \mathrm{C}$.

Aliquots of total mucosal homogenate and microsome fractions were submitted to lipid extraction according to the method of Folch et al. (29). Total lipid classes were separated by TLC using silica gel G in a solvent of petroleum ether/ethyl ether/glacial acetic acid (80:20:1; vol/ $\mathrm{vol} / \mathrm{vol})$. Samples were identified by comparison to standards, scraped into Teflon-lined screw-capped tubes and transmethylated directly using 14\% $\mathrm{BF}_{3}$-methanol (30), following addition of heptadecanoic acid as an internal standard. The derivitized fatty acids were assayed using a gas liquid chromatograph (model 8410; Perkin-Elmer, Norwalk, CT) equipped with a $6 \mathrm{ft} \times 2 \mathrm{~mm}$ i.d. column packed with $10 \%$ SP-2330 on 100/120 mesh chromasorb (Supelco, Inc., Bellefonte, PA). Authentic fatty acid methyl esters (Nu-Chek-Prep, Elysian, MN) were used to identify peaks based on their relative retention times. Values were calculated as micrograms of fatty acid (FA) and normalized to protein values (20). Microsome phospholipid content was determined on total lipid extracts by the method of Bartlett (31).

Chemicals and preparation of test infusates. L $\alpha$-Dioleoyl-phosphatidylcholine (PC) and lysophosphatidylcholine were purchased from Avanti Polar Lipids, Inc. (Birmingham, AL). L-3 Dipalmitoyl phosphatidylcholine ether was purchased from Serdary Research Laboratories (London, Ontario). Taurine conjugated bile salts (sodium salt) were purchased from Calbiochem, La Jolla, CA. Cholesterol was 
purchased from Nu-Chek-Prep. Oleic acid was purchased from Sigma Chemical Co., St. Louis, MO. Liposomes containing PC and cholesterol in a 3:1 molar ratio were prepared as described (32) but with the following modifications. Stock solutions of PC in hexane were evaporated under $\mathrm{N}_{2}$ and subsequently lyophilized for $30 \mathrm{~min}$ under vacuum. Cholesterol was added, the mixture suspended in $10 \mathrm{ml} \mathrm{D10-sa-}$ line at $4^{\circ} \mathrm{C}$ and then sonicated under $\mathrm{N}_{2}$ at $50 \mathrm{~W}$ for ten 3-min bursts. The mixture was kept on ice throughout the procedure and the volume adjusted to give a final $P C$ concentration of $2 \mathrm{mM}$, a value representative of biliary PC concentrations in the rat (33). The infusate was observed to be clear in every case and was used within $1 \mathrm{~h}$ of preparation. Mass determination of lipid phosphorus (31) indicated that typically $>90 \%$ of expected PC was recovered. TLC using silica G in a solvent system of chloroform/methanol/glacial acetic acid/water (50:30:8:6; vol/vol/vol/vol) indicated that $>96 \%$ of the phospholipid phosphorus was accounted for by phosphatidylcholine both pre- and postsonication, suggesting that no substantial breakdown had taken place. In some experiments, where indicated, $L-\alpha$-dioleoyl [dioleoyl-l${ }^{14} \mathrm{C}$ ]phosphatidylcholine (New England Nuclear, Boston, MA) was added to the infusate. This material was observed to be $>98 \%$ pure by TLC. Infusions of bile salts were adjusted to $\mathrm{pH} 7.0$ using $0.1 \mathrm{M}$ $\mathrm{NaOH}$. Infusions of fatty acid were prepared using the method of Gebhard (32) with some modification. $200 \mathrm{ml}$ of a $0.1 \%$ solution of gelatin hydrolysate (Sigma) was prepared in warm D10-saline. To this was added, dropwise, $100 \mu \mathrm{l}$ ethanol containing oleic acid at a final concentration as described in the text and where indicated, $\sim 10 \mu \mathrm{Ci}$ 1- $\left[{ }^{14} \mathrm{C}\right]$ oleic acid (New England Nuclear). The (visually opaque) mixture was adjusted to $\mathrm{pH} 8.0$ with $1 \mathrm{M} \mathrm{NaOH}$ and sonicated under $\mathrm{N}_{2}$, at $4^{\circ} \mathrm{C}$, for five 3 -min bursts at $50 \mathrm{~W}$. The now optically clear solution was infused immediately.

Miscellaneous assays. Lumenal contents and mucosal scrapings were assayed for bile salt concentration using an enzymatic method (34). Protein determinations (20) used bovine serum albumin as a standard.

Statistics. Statistical comparisons were made using independent $t$ tests and employed both methods for pooled and separate variance where appropriate. Data, unless otherwise stated, are expressed as mean \pm SD.

\section{Results}

\section{Intestinal apo $B_{48}$ synthesis}

Regulation by bile salt flux. In previous studies (4) we demonstrated that a 14-h infusion of $10 \mathrm{mM} \mathrm{Na}$ taurocholate resulted in complete reexpression of jejunal apo $\mathrm{B}_{\mathbf{4 8}}$ synthesis following $30 \mathrm{~h}$ of bile diversion. As shown in Fig. 1, this study shows that this effect is produced by infusion of $5 \mathrm{mM}$ but not $2 \mathrm{mM} \mathrm{Na}$ taurocholate suggesting that concentrations close to the critical micellar concentration (CMC) may be required. The effects of equimolar $(5 \mathrm{mM})$ infusion of four different taurine conjugated bile salts upon intestinal apo $B_{48}$ synthesis are documented in Fig. 2. Two major observations were made. First, structurally distinct bile salts had different effects on reexpression of jejunal apo $\mathbf{B}_{48}$ synthesis following bile diversion (Fig. 2 A). $5 \mathrm{mM} \mathrm{Na}$ taurodeoxycholate produced the greatest apparent stimulation while $5 \mathrm{mM}$ NaTUDCA had no apparent effect (bile diverted $0.47 \pm 0.12 \%, n=10$, NaTUDCA $0.46 \pm 0.10 \%, n=5$ ). Further studies using $10 \mathrm{mM}$ NaTUDCA revealed complete reexpression of jejunal apo $\mathrm{B}_{\mathbf{4 8}}$ synthesis $(0.87 \pm 0.03 \%, n=4)$ with no further increase in two animals studied following $15 \mathrm{mM}$ NaTUDCA infusion $(0.79 \%$ and $0.68 \%$ ). This suggests that a dose-response relationship exists for structurally distinct bile salts. Secondly, despite apparently complete reexpression of jejunal apo $B_{48}$ synthesis, ileal apo

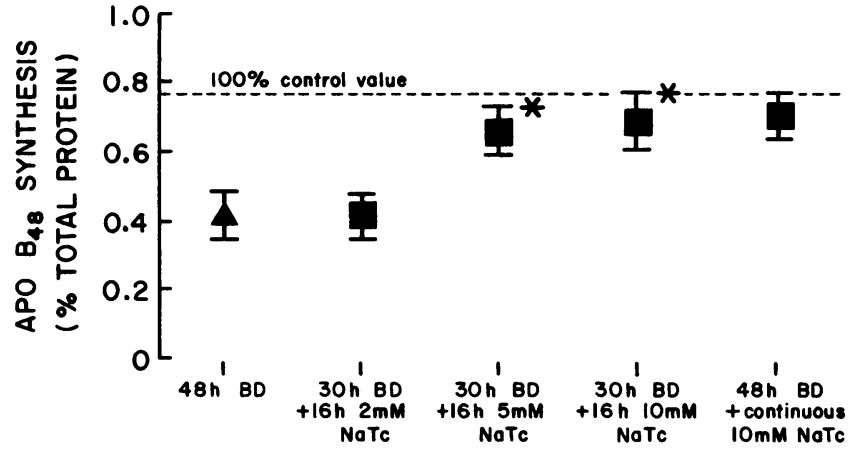

Figure 1. Jejunal apo $\mathrm{B}_{48}$ synthesis in bile diverted rats. Reexpression with increasing concentrations of $\mathrm{Na}$ taurocholate. Animals $(n$ = 4-10 per group) were subjected to external bile diversion (BD) and infused via duodenal cannula with D10-saline for $30 \mathrm{~h}$ (Methods). The infusate was changed for the last $18 \mathrm{~h}$ of study to D10-saline containing 2,5, or $10 \mathrm{mM} \mathrm{Na}$ taurocholate and apo $\mathrm{B}_{48}$ synthesis rates determined in jejunal enterocytes (Methods). Data are mean \pm standard error. *Indicates significantly different to $\mathrm{BD}$ alone, $P<0.05$.

$B_{48}$ synthesis was incompletely reexpressed after intraduodenal bile salt replacement (Fig. $2 \mathrm{~B}$ ). This is analogous to our findings with respect to ileal apo A-I synthesis after bile diversion (35), and suggests that factors other than lumenal bile salt replacement alone are necessary for reexpression of apo $\mathbf{B}_{48}$ synthesis in this region.

It was found that intraduodenal infusion of $5 \mathrm{mM} \mathrm{Na}$ taurocholate produced lumenal bile salt concentrations in the ileum (mean $11.0 \mu \mathrm{M}$, range 3.1-18, $n=3$ ) comparable to those in jejunal contents (mean 3.5 $\mu \mathrm{M}$, range 2.7-5.0, $n=3$ ). Additionally, mucosal concentrations of bile salt were somewhat higher in ileal samples $(1.3-1.8 \mathrm{nmol} / \mathrm{mg}$ ) versus jejunal samples $(0.50-0.52 \mathrm{nmol} / \mathrm{mg})$. Taken together, this suggests that differences in delivery or mucosal uptake are insufficient to account for the regional effects observed on apo $B_{48}$ synthesis reexpression following bile salt replacement.

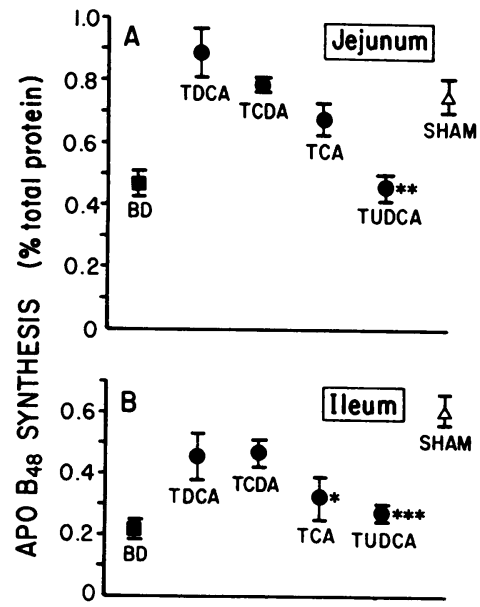

Figure 2. Intestinal apo $\mathrm{B}_{48}$ synthesis in bile diverted rats. Effects of equimolar infusion of 4 taurine-conjugated bile salts. Animals ( $n$ $=4-10$ per group) were subjected to external $B D$ as described above (Methods and legend to Fig. 1). The infusate was changed for the last $18 \mathrm{~h}$ of study to contain $5 \mathrm{mM}$ TDCA, Na taurochenodeoxycholate (TCDA), $\mathrm{Na}$ taurocholate (TCA) or Na tauroursodeoxycholate (TUDCA) Apo $B_{48}$ synthesis rates were determined in both je-

junal $(A)$ and ileal $(B)$ enterocytes (Methods) and the data illustrated as mean \pm standard error. *Indicates significantly different to sham, $P$ $<0.01$. ${ }^{* *}$ Indicates significantly different to sham, $P<0.0025$. ***Indicates significantly different to sham, $P<0.0005$. 


\section{Intestinal apo $B_{48}$ synthesis}

Regulation by lumenal lipid uptake. To pursue the mechanism of bile salt-mediated reexpression of jejunal apo $B_{48}$ synthesis, we tested the hypothesis that reexpression was related to facilitated uptake of critical lumenal lipid components, potentially fatty acid or sterol. The role of fatty acid uptake was studied directly in experiments described in the legend to Fig. 3. Animals infused with a micellar mixture of $2 \mathrm{mM} \mathrm{Na}$ taurocholate $/ 2 \mathrm{mM}$ oleic acid/2 $\mathrm{mM}$ monoolein were noted to have complete reexpression of apo $B_{48}$ synthesis in both jejunum (Fig. $3 \mathrm{~A}$ ) and ileum (Fig. $3 \mathrm{~B}$ ). By contrast, $2 \mathrm{mM} \mathrm{Na}$ taurocholate alone was ineffective in mediating reexpression of jejunal apo $\mathrm{B}_{48}$ synthesis (Fig. $3 \mathrm{~A}$ ), while $5 \mathrm{mM} \mathrm{Na}$ taurocholate failed to alter ileal apo $B_{48}$ synthesis.

To demonstrate conclusively that fatty acid uptake per se was responsible for the observed effect, animals were infused with $2 \mathrm{mM}$ oleic acid (as the sodium "soap," see Methods) for 16-18 $\mathrm{h}$ and apo $\mathrm{B}_{48}$ synthesis rates determined to be reexpressed to $85 \pm 17 \%$ control levels in jejunal enterocytes (Fig. 3 $A$ ). Ileal apo $\mathrm{B}_{48}$ synthesis rates, however, were incompletely restored (FA infused $0.42 \pm 0.11(n=4)$ versus sham $0.61 \pm 0.15, n=8, P<0.05$ ). This may reflect differences in lumenal fatty acid concentration in the distal small intestine, although this was not specifically investigated. Additional studies demonstrated that $1 \mathrm{mM}$ oleic acid was equally effective in reexpressing jejunal apo $B_{48}$ synthesis $(84 \pm 13 \%$ control levels, $n=4, P>0.05)$. The distribution of $1-\left[{ }^{14} \mathrm{C}\right]$ oleic acid into mucosal lipid subclasses was found to be predominantly $(>80 \%)$ as complex lipid (phospholipid, cholesteryl ester, triglyceride) with only $16.5 \pm 2.5 \%$ of the counts remaining as free fatty acid.

The role of sterol uptake was investigated in one experiment where 5 bile diverted rats were infused with $0.25 \mathrm{mM}$ $25-\mathrm{OH}$ cholesterol in $0.5 \%$ ethanol-10\% dextrose-saline. This concentration has previously been shown (32) to suppress in vivo intestinal cholesterol synthesis in dogs. Apo $B_{48}$ synthesis rates (jejunum $0.58 \pm 0.08 \%$; ileum $0.35 \pm 0.15 \%$ ) were no different than bile diverted animals receiving D10 saline alone (jejunum $0.47 \pm 0.12, n=10$; ileum $0.22 \pm 0.11, n=10$ ). This

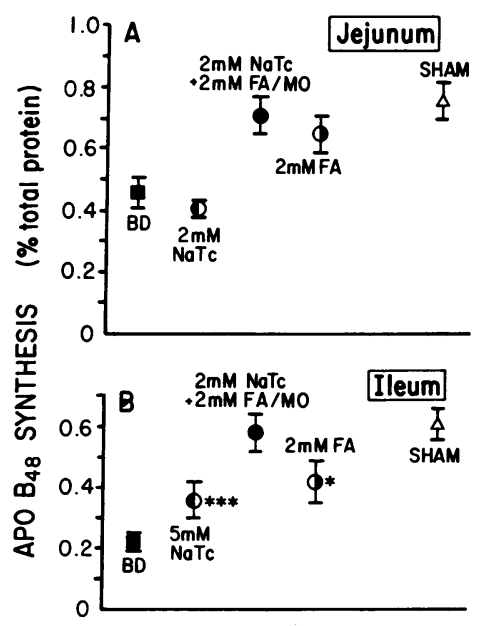

Figure 3. Intestinal apo $\mathrm{B}_{48}$ synthesis in bile diverted rats. Reexpression following lumenal fatty acid uptake. Animals $(n=4-10$ per group) were subjected to external bile diversion as described above (Methods and Fig. 1). The infusate was changed for the last 18 h of study to contain 2 or 5 mM Na taurocholate $(\mathrm{NaTc})$ alone or as a micellar mixture of $2 \mathrm{mM}$ oleic acid-2mM mono-olein (NaTc/FA/MO). A separate group received an infusion of $2 \mathrm{mM}$ oleic acid without detergent solubilization (Methods). Apo $\mathbf{B}_{\mathbf{4 8}}$ synthesis rates were determined in both jejunal $(A)$ and ileal $(B)$ enterocytes (Methods) and the data illustrated as mean \pm standard error. *Indicates significantly different to sham, $P<0.05$. ${ }^{* * *}$ Indicates significantly different to sham, $P$ $<0.0005$. suggests that the bile salt-mediated reexpression of apo $B_{48}$ synthesis is not related to facilitated uptake of lumenal sterol.

\section{Intestinal apo $B_{48}$ synthesis}

Regulation by lumenal phospholipid uptake. Groups of bilediverted animals were infused with different preparations of phospholipid as detailed in the legend to Fig. 4. Animals infused with PC-cholesterol liposomes (2 mM PC: $0.625 \mathrm{mM}$ cholesterol) were found to have a further 50\% suppression of apo $B_{48}$ synthesis rates in jejunal enterocytes below those found in bile diverted animals (Fig. $4 A, 0.23 \pm 0.08(n=4)$ versus $0.47 \pm 0.12(n=10), P<0.005)$. These same animals, by contrast, were found to have an almost sixfold elevation in ileal apo $B_{48}$ synthesis rates (Fig. $\left.4 B\right)(1.26 \pm 0.32[n=4]$ versus $0.22 \pm 0.11[n=10], P<0.001)$.

Further studies were conducted to elucidate the mechanism for this striking regional effect of PC-cholesterol liposome infusion. Animals were infused with PC-cholesterol liposomes containing $L \alpha$-dioleoyl[dioleoyl- $1-{ }^{14} \mathrm{C}$ ]PC. At the conclusion of the infusion, the entire small intestine was removed, divided into proximal, middle and distal thirds and mucosal scrapings subjected to lipid extraction and analysis by TLC (see Methods). Phospholipid uptake (nmol $\left[{ }^{14} \mathrm{C}\right] \mathrm{PC} / \mathrm{mg}$ intestinal mucosal protein) was found to increase progressively from proximal $(0.55 \pm 0.13)$ to middle $(1.29 \pm 0.87)$ to distal $(2.11 \pm 0.58)$ small bowel. This suggests that lumenal digestion of phospholipid is relatively inefficient following bile diversion with mucosal uptake of the lipolytic products presumably taking place more distally in the small bowel (as discussed below).

The relationship of these events to the regulation of intestinal apo $B_{48}$ synthesis was explored in further studies in which $2 \mathrm{mM}$ PC- $0.625 \mathrm{mM}$ cholesterol was infused as a mixed micellar solution with $2 \mathrm{mM} \mathrm{Na}$ taurocholate. As demonstrated

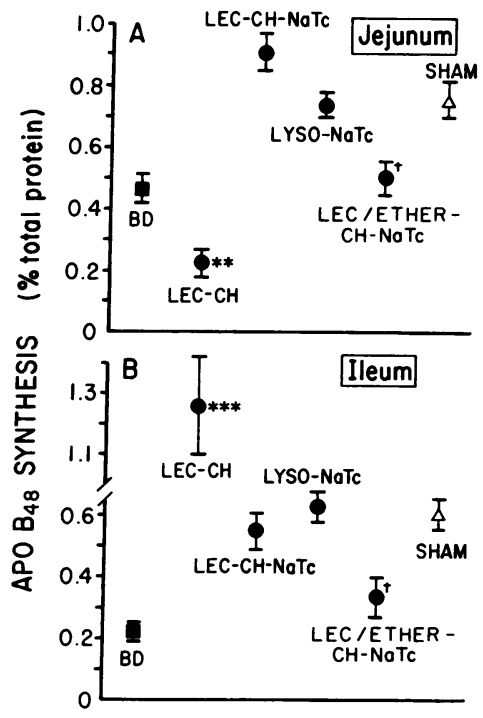

Figure 4. Intestinal apo $B_{48}$ synthesis in bile-diverted rats. Regulation by lumenal phospholipid uptake. Animals $(n=4-10$ per group) were subjected to external bile diversion as described above (Methods and legend to Fig. 1). The infusate was changed for the last $18 \mathrm{~h}$ of study to contain a liposomal suspension of lecithin-cholesterol (3:1 molar ratio) prepared as described in Methods. Alternatively, animals were infused with a micellar mixture of lecithin-cholesterol-Na taurocholate (2:0.625: $2 \mathrm{mM}$, respectively) using either natural L phosphatidylcholine (LEC-CH-NaTc) or a synthetic preparation of L-3 phosphatidylcholine dipalmitoyl ether (LEC/ ETHER-CH-NaTc). Other animals were infused with $2 \mathrm{mM}$ lysolecithin-2 mM Na taurocholate (LYSO-NaTc). Apo $\mathrm{B}_{48}$ synthesis rates were determined in jejunal $(A)$ and ileal $(B)$ enterocytes and the data illustrated as mean \pm standard error. ${ }^{* *}$ Indicates significantly different to bile diversion alone (BD), $P<0.005$. $^{* * *}$ Indicates significantly different to sham, $P<0.001$. ${ }^{+}$Indicates significantly different to sham, $P<0.005$. 
in Fig. $4 A$, apo $B_{48}$ synthesis was completely reexpressed in jejunal enterocytes. This suggests that hydrolysis of lumenal PC in the proximal jejunum is facilitated by the presence of the bile salts and may be critical to the phospholipid-mediated reexpression of jejunal apo $B_{48}$ synthesis. Additionally, apo $B_{48}$ synthesis was reexpressed to control levels in ileal enterocytes by this maneuver (Fig. $4 B$ ). To further emphasize a possible role for lumenal phospholipid metabolism in the regulation of intestinal apo $B_{48}$ synthesis, animals infused with $2 \mathrm{mM}$ lysolecithin-2 mM Na taurocholate were found to have complete (97\% control) reexpression of apo $B_{48}$ synthesis in both jejunum and ileum (Fig. 4, $A$ and $B$ ). Animals infused with 2 $\mathrm{mM}$ lysolecithin alone had comparable reexpression of jejunal apo $B_{48}$ synthesis $(85 \pm 24 \%$ control, $n=4, P>0.05)$. As a final control, animals infused with a micellar mixture of $2 \mathrm{mM}$ PC-ether- $0.625 \mathrm{mM}$ cholesterol-2 $\mathrm{mM} \mathrm{Na}$ taurocholate were found to have values for apo $B_{48}$ synthesis in both jejunal and ileal enterocytes no different than bile diverted animals (Fig. 4, $A$ and $B$ ). In this experiment, the inability to hydrolyze lecithin-ether and the subsequent failure to generate lysophospholipid and fatty acid prevented reexpression of intestinal apo $B_{48}$ synthesis. Taken together, the evidence strongly suggests a physiologic role for lumenal phospholipid metabolism in the regulation of intestinal apo $B_{48}$ synthesis.

\section{Jejunal apo $B_{48}$ reexpression in bile diverted animals}

Relationship to parameters of mucosal lipid content. To explore the mechanism(s) by which bile salt, fatty acid, and phospholipid infusion mediate the reexpression of jejunal apo $\mathbf{B}_{48}$ synthesis, bile-diverted animals were infused with these separate preparations as described above. Total mucosal and microsome samples were prepared from each animal in addition to measurement of in vivo apo $\mathbf{B}_{48}$ synthesis rates. Values for microsome lipid content are presented in Table I which demonstrates a significant and uniform increase in triglyceride fatty acid content following infusion of $5 \mathrm{mM} \mathrm{Na}$ taurocholate (apo $\mathrm{B}_{48}$ synthesis $93 \pm 32 \%$ control), $2 \mathrm{mM}$ lysophospholipid (apo $B_{48}$ synthesis $85 \pm 24 \%$ control) and $1 \mathrm{mM}$ fatty acid (apo $B_{48}$ synthesis $84 \pm 13 \%$ control) compared to bile diversion alone (apo $\mathrm{B}_{48}$ synthesis $53 \pm 3 \%$ control). When all the groups

Table I. Jejunal Microsome Lipid Content

\begin{tabular}{|c|c|c|c|c|}
\hline Group & $n$ & Triglyceride & Free fatty acid & Phospholipid \\
\hline & & \multicolumn{2}{|c|}{$\mu g F A / m g$ protein } & nmol/mg protein \\
\hline Bile diverted & (4) & $90 \pm 38$ & $798 \pm 140$ & $0.94 \pm 0.33$ \\
\hline Sham & (6) & $382 \pm 192^{*}$ & $887 \pm 614$ & $1.32 \pm 0.66$ \\
\hline $\mathrm{BD}+5 \mathrm{mM} \mathrm{NaTc}$ & (5) & $521 \pm 245^{\ddagger}$ & $1,370 \pm 626$ & $1.01 \pm 0.49$ \\
\hline $\mathrm{BD}+2 \mathrm{mM}$ LYSO & (5) & $217 \pm 89^{*}$ & $559 \pm 45^{*}$ & $1.25 \pm 0.61$ \\
\hline $\mathrm{BD}+1 \mathrm{mM}$ FA & (4) & $329 \pm 168^{*}$ & $553 \pm 133$ & $1.54 \pm 0.25^{*}$ \\
\hline
\end{tabular}

Animals were bile diverted or subjected to a sham procedure and infused via duodenal cannula with D10 saline. For the last $18 \mathrm{~h}$ of study, groups of $(n)$ animals received $5 \mathrm{mM} \mathrm{Na}$ taurocholate (NaTc) alone, $2 \mathrm{mM}$ lysolecithin (Lyso) alone or $1 \mathrm{mM}$ oleic acid (FA) alone as described in Methods. Microsomes were prepared as described and triglyceride and free fatty acid mass determined by GLC. Phospholipid was assayed as lipid phosphorus. Data are mean \pm SD for $(n)$ animals. Differences were determined by independent $t$ test comparison to bile-diverted animals.

${ }^{*} P<0.05,{ }^{\ddagger} P<0.02$. were compared, microsome triglyceride content was found to be significantly correlated $(r=0.65, P<0.005)$ with jejunal apo $B_{48}$ synthesis (Fig. 5). There was no increase in microsome free-fatty acid or phospholipid content in the setting of jejunal apo $B_{48}$ synthesis reexpression (Table I). Mucosal free fatty acid concentrations were lower in both sham operated $(161 \pm 82 \mu \mathrm{g} / \mathrm{mg})$ and fatty acid infused $(143 \pm 50 \mu \mathrm{g} / \mathrm{mg})$ animals compared to bile diverted animals $(337 \pm 125 \mu \mathrm{g} / \mathrm{mg}, P$ $<0.05)$. No significant changes were found in the bile salt and lysolecithin infused animals $(461 \pm 218$ and $220 \pm 103 \mu \mathrm{g} / \mathrm{mg}$, respectively). Total mucosal triglyceride fatty acid content was decreased in bile diverted animals $(28 \pm 13 \mu \mathrm{g} / \mathrm{mg}$ protein) compared to shams $(110 \pm 40 \mu \mathrm{g} / \mathrm{mg}, P<0.01)$ and animals infused with $5 \mathrm{mM} \mathrm{Na}$ taurocholate $(166 \pm 110 \mu \mathrm{g} / \mathrm{mg}, P$ $<0.05$ ) but no increase was found in the other two groups and no significant correlation was found overall with apo $B_{48}$ synthesis $(r=0.22, P>0.05$, NS).

The evidence (from Fig. 5) suggests that microsome triglyceride content may be an important determinant of intestinal apo $B_{48}$ synthesis rates in animals subjected to depletion of lumenal (dietary and biliary) lipid substrate. It should be stressed, however, that we had previously found no regulation of intestinal apo $\mathbf{B}_{48}$ synthesis rates in animals (with intact biliary anatomy) subjected to either acute (4) or sustained (36) intake of triglyceride. When groups of 48-h fasted, chow-fed rats were challenged with either $1 \mathrm{~g}$ dextrose or $1 \mathrm{~g}$ fat, the latter group demonstrated a 16 -fold increase in mucosal triglyceride content $(110 \pm 40 \mu \mathrm{g} / \mathrm{mg}, n=4$ versus $1,803 \pm 876$ $\mu \mathrm{g} / \mathrm{mg}, n=4$ ) and a more modest increase in microsome triglyceride content $(382 \pm 192 \mu \mathrm{g} / \mathrm{mg}$ versus $561 \pm 43 \mu \mathrm{g} / \mathrm{mg})$. Apo $\mathrm{B}_{48}$ synthesis rates were strictly comparable $(1.35 \pm 0.35 \%$ versus $1.43 \pm 0.24 \%$ ). These data suggest that there may be a threshold level of microsomal triglyceride accumulation in

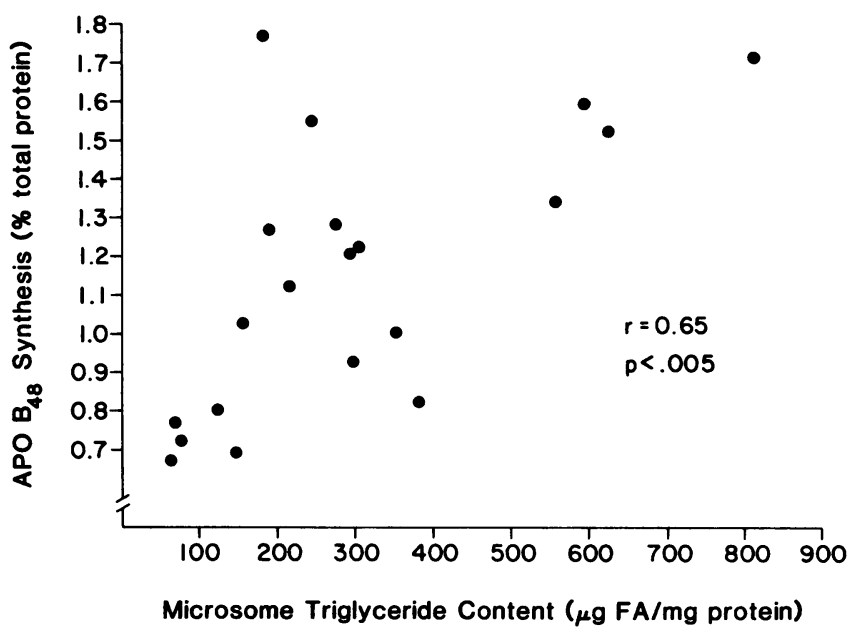

Figure 5. Jejunal apo $\mathbf{B}_{48}$ synthesis. Reexpression following bile diversion is related to microsome triglyceride content. Groups of animals were subject to bile diversion or sham operation ( $n=4-6$ per group) and infused via duodenal cannula with D10 saline. For the last $18 \mathrm{~h}$ of study, treated animals received $5 \mathrm{mM}$ Na taurocholate, 2 $\mathrm{mM}$ lysolecithin or $1 \mathrm{mM}$ oleic acid. Bile diverted and sham operated animals received only D10 saline. Jejunal apo $B_{48}$ synthesis rates were determined (Methods) and microsomes prepared from the remaining proximal small intestine for assay of triglyceride-fatty acid mass by GLC (Methods). The equation for the regression is $y$ $=0.0011, x+0.82$. 
animals with an intact enterohepatic circulation, which may maintain intestinal apo $B_{48}$ synthesis rates at levels sufficient to accommodate chylomicron assembly and secretion during periods of augmented mucosal triglyceride flux.

\section{Intestinal apo $B_{48}$ synthesis}

Relationship of in vivo synthesis rates to the abundance of apo $B m R N A$. RNA blot hybridization analysis of total cellular RNA prepared from the jejunum and ileum of bile diverted and sham operated animals revealed similar patterns of apo B mRNA abundance (Table II). Furthermore, bile diverted animals infused with lecithin-cholesterol liposomes for $18 \mathrm{~h}$ before study also demonstrated comparable values for total apo B mRNA abundance to bile diverted or sham operated controls (Table II). Thus, over a wide range of intestinal apo $B_{48}$ synthesis rates, mRNA abundance for apo $B$ was unchanged. Analysis of both intestinal and hepatic apo B mRNA size distribution following formaldehyde-agarose electrophoresis demonstrated a polydisperse population with major bands at $\sim 7$ and $15 \mathrm{~kb}$ (Figs. 6, $A$ and $C$ ). The higher molecular weight band was found to demonstrate variable intensity based on inconsistent transfer (compare identical liver standard in Fig. 6, $A$ and $C$ ). Although degradation of high molecular weight apo B RNAs cannot be completely excluded, all preparations of intestinal and hepatic RNA were determined to be "intact" by methylmercury electrophoresis (22) (data not shown). Additionally, analysis of intestinal apo AIV mRNA demonstrated equivalent and intact message of appropriate size (26), in both bile-diverted and sham-operated animals (Fig. $6 \mathrm{~B}$ ), while hepatic RNA demonstrated a single band following hybridization to fibronectin cDNA (Fig. $6 \mathrm{D}$ ).

\section{Discussion}

These studies were undertaken to examine the restoration of intestinal apo $B_{48}$ synthesis by elements of biliary lipid flux. Such a role had been postulated in a previous report (4) in which reexpression of intestinal apo $B_{48}$ synthesis was observed in a regional and time-dependent manner following infusion

Table II. Intestinal Apo B mRNA Abundance: Effects of Bile Diversion and Reintroduction of Model Components of Rat Bile In Vivo

\begin{tabular}{|c|c|c|}
\hline & Jejunum & Ileum \\
\hline & \multicolumn{2}{|c|}{$\begin{array}{l}\text { \% Control intestinal apo B } \\
m R N A \text { abundance }\end{array}$} \\
\hline Sham & $63 \pm 27(8)$ & $58 \pm 19(8)$ \\
\hline Bile diversion & $75 \pm 40(9)$ & $52 \pm 11(9)$ \\
\hline \multicolumn{3}{|c|}{ Bile diversion + lecithin cholesterol } \\
\hline liposomes & $72 \pm 22(5)$ & $42 \pm 17(5)$ \\
\hline
\end{tabular}

Animals were bile diverted or subjected to a sham procedure and infused via duodenal cannula with D10-saline. In one group of animals the infusate was changed for the last $18 \mathrm{~h}$ of study to contain lecithin-cholesterol liposomes (3:1 molar ratio, Methods). Jejunal and ileal total cellular RNA (pooled from 1-3 animals) was analyzed by dot-blot hybridization. Relative apo B mRNA abundance was calculated by scanning laser densitometry and data compared to an intestinal RNA standard. Data are expressed as mean \pm SD for $(n)$ pools of total RNA. Differences were determined by independent $t$ test to be not significant. $P>0.05$. of $10 \mathrm{mM} \mathrm{Na}$ taurocholate into bile diverted rats. It was established in these and more recent (36) studies that jejunal apo $\mathbf{B}_{\mathbf{4 8}}$ synthesis rates were unchanged from fasting levels by either acute or sustained augmentation of triglyceride intake. Thus, the hypothesis has emerged that jejunal apo $\mathrm{B}_{48}$ gene expression in the fasting adult rat may represent its fully induced state. Additionally, recent evidence that intestinal apo B mRNA abundance changes during development in the rat (19), provided further impetus to examine the role of lumenal lipid components in mediating these effects.

The bile-salt mediated reexpression of intestinal apo $\mathbf{B}_{48}$ synthesis demonstrated both dose and structural dependency in addition to regional specificity. Potential mechanisms of action in mediating reexpression of jejunal apo $B_{48}$ synthesis include a direct effect of bile salt uptake per se or an effect mediated by facilitated uptake of other lumenal lipid components. Evidence against the former hypothesis is provided by the finding of similar bile salt concentrations in both jejunal and ileal enterocytes while apo $B_{48}$ synthesis rates were restored in only the proximal small intestine.

Evidence from studies presented above suggests that lumenal fatty acid uptake is a key regulatory event in mediating reexpression of intestinal apo $B_{48}$ synthesis. The apparent relationship between lumenal fatty acid uptake and bile-salt dependent reexpression of jejunal apo $B_{48}$ synthesis may reflect a number of mechanisms. First, it could be related to facilitated lumenal hydrolysis of membrane phospholipid (37). In this regard, the greater efficacy with which the more hydrophobic bile salts (38) mediated the restoration of jejunal apo $B_{48}$ synthesis may relate to their demonstrated ability to promote adsorption of phospholipase $A_{2}$ to its substrate (membrane phospholipid) (37). A second possibility is that intestinal bile salt uptake influences the turnover of membrane phospholipidsparticularly phosphatidylinositol-resulting in diacylglycerol production and subsequent reexpression of apo $\mathbf{B}_{\mathbf{4 8}}$ synthesis $(39,40)$. An observation of key importance in regard to the possible mechanism of apo $B_{48}$ synthesis restoration by either fatty acid or bile salt infusion is the parallel reaccumulation of microsome triglyceride (Fig. 5). It may be speculated that in both situations, fatty acid may be preferentially diverted into triglyceride which, at low levels of production, would undergo rapid turnover and secretion into mesenteric lymph $(41,42)$. It bears emphasis in this regard that plasma free fatty acids, which may be an important substrate for enterocytes in the absence of lumenal lipid (43) may play a role in the bile saltdependent reexpression of apo $B_{48}$ synthesis. The present studies do not exclude such a possibility.

The data suggest an important role for lumenal phospholipid flux in mediating the restoration of both jejunal and ileal apo $B_{48}$ synthesis. Several aspects of these studies deserve additional comment. First, lecithin-cholesterol liposomes were prepared at concentrations equal to those reported for biliary phospholipid and cholesterol concentrations in the rat (33). Liposomes were prepared at a 3:1 molar ratio (PC/cholesterol) and thus were presumably unsaturated with respect to cholesterol and potentially fatty acid (44). This speculation, although not specifically investigated in the present report, may explain the significant decrease noted in jejunal apo $B_{48}$ synthesis following lecithin-cholesterol liposome infusion since it may reflect net egress of mucosal lipid $(44,45)$. Infusion of [dioleoyl$\left.1-{ }^{14} \mathrm{C}\right]$ phosphatidylcholine/cholesterol liposomes documented the almost fourfold higher uptake of phospholipid in the distal small intestine compared to proximal jejunum (above) and 

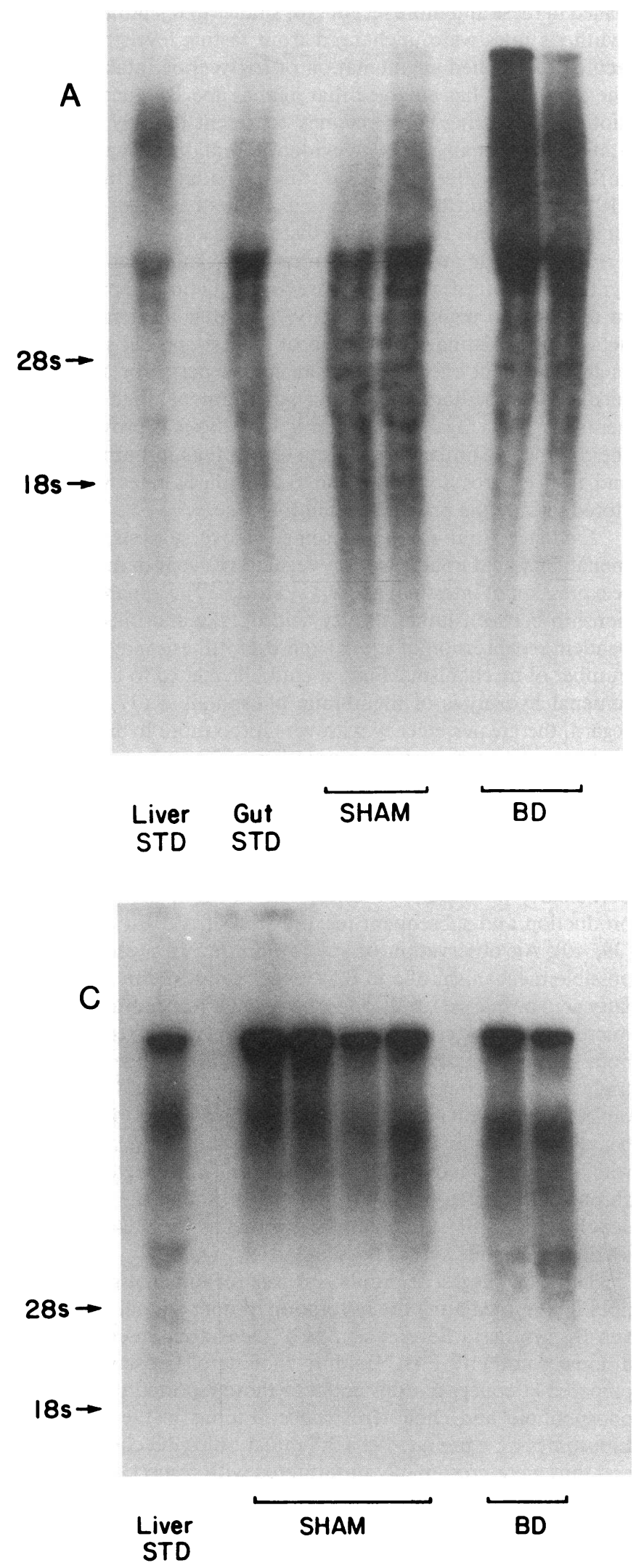

Figure 6. Northern gel analysis of intestinal and hepatic RNA following bile diversion. Animals were subjected to bile diversion or sham operation as described above (Methods). Total cellular RNA was extracted in parallel from proximal small intestine and liver. Aliquots $(25 \mu \mathrm{g})$ of total RNA were fractionated through $0.75 \%$ agarose/6\%
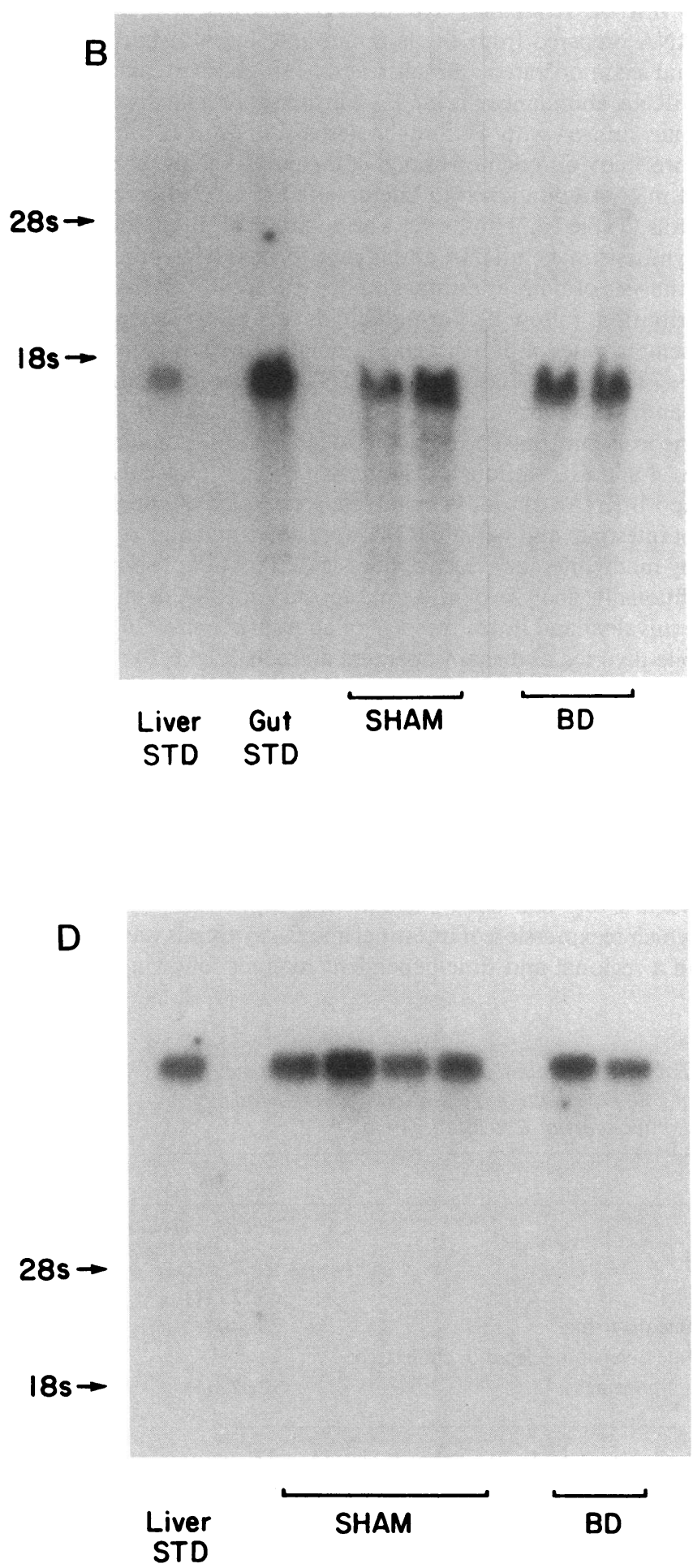

formaldehyde slab gels, and transferred to nitrocellulose. ( $A$ and $B$ ) Intestinal RNA samples probed with cDNA to rat apo $B$ and apo A-IV (Methods) ( $C$ and $D$ ) Hepatic RNA samples probed with cDNA to rat apo B and fibronectin (Methods). BD, bile diverted. The migration of $28_{\mathrm{s}}$ and $18_{\mathrm{s}}$ ribosomal RNA is shown. 
thus provides further support for the hypothesis that the sixfold induction of ileal apo $B_{48}$ synthesis demonstrated in these animals is linked to regional differences observed in lumenal phospholipid hydrolysis. This is consistent with other data showing phospholipase A2 activity is three to four times greater in the distal compared to proximal small intestine $(46,47)$.

At least two possible mechanisms exist for the restoration of apo $B_{48}$ synthesis, related to each of the major lipolytic products of lumenal phospholipid hydrolysis. One possibility is that generation of fatty acid from lumenal phospholipid hydrolysis produces reexpression of apo $\mathrm{B}_{48}$ in a manner analogous to that observed following infusion of fatty acid alone. A second possibility is that reexpression of apo $\mathbf{B}_{48}$ synthesis, particularly in the distal small intestine, may be related to intracellular phospholipid reassembly. Evidence is available to support both possibilities. In favor of fatty acid generation being the operative mechanism is the observation of increased microsome triglyceride content without demonstrable alteration in microsome phospholipid content following lysolecithin infusion (Table I). However an alternative possibility is that subtle changes in microsome phospholipid metabolism, not reflected by content measurements, may influence intestinal TG synthesis either by altering glycerolipid substrate availability or the conformation and activity of various microsomal enzymes of triglyceride assembly (48). Evidence in support of lysolecithin and its directed reassembly into cellular phosphatidylcholine as being a key factor in mediating the restoration of apo $\mathrm{B}_{48}$ synthesis is somewhat less direct. Although the restoration of both jejunal and ileal apo $B_{48}$ synthesis following $2 \mathrm{mM}$ lysolecithin infusion is consistent with a potential role for intestinal phospholipid reassembly, other workers have suggested that lysolecithin may not be stoichiometrically reacylated to phosphatidylcholine (49) but rather undergoes degradation and thereby provides substrate for TG synthesis. Mucosal lipid extracts from animals infused with L $\alpha\left[1-{ }^{14} \mathrm{C}\right.$-dioleoyl $]$ phosphatidylcholine-cholesterol liposomes were found to have over $98 \%$ of ${ }^{14} \mathrm{C}$ counts from ileal mucosal extracts comigrate with phospholipid with $1.7 \pm 0.6 \%$ of the ${ }^{14} \mathrm{C}$ counts comigrating with triglyceride on TLC. $80-84 \%$ of the phospholipid radioactivity was associated with phosphatidylcholine, the other major class being phosphatidylethanolamine (10-12\%). Finally, the fatty acid distribution of microsome triglyceride revealed no relative enrichment in 16:0 species following $2 \mathrm{mM}$ lysolecithin (predominantly palmitoyl) infusion (bile diverted $37.3 \pm 7.2 \%$, sham $33.0 \pm 9.7 \%$ versus lysolecithin $25.5 \pm 5.1 \%$ ). Thus a consensus of data suggests that the bulk of lumenal lysophospholipid appears destined for uptake and reacylation into lecithin and in this regard may be the preferred substrate (50-52). The integrated regulation of intestinal phospholipid metabolism and triglyceride-rich lipoprotein secretion has been proposed by other workers (41) but details of the mechanisms of phospholipid-enhanced intestinal triglyceride secretion are currently unknown.

The cumulative evidence suggests that biliary lipid flux may maintain threshold levels of microsomal triglyceride and facilitates maximal expression of intestinal apo $\mathbf{B}_{\mathbf{4 8}}$ synthesis which is subsequently unaltered by further increases in cellular TG flux. A further conclusion of these studies is that the changes described in the synthesis rates of intestinal apo $B_{48}$, in vivo, were not accompanied by detectable changes in apo $B$ mRNA abundance. The implication, yet to be proved, is that the observed alterations in apo $B_{48}$ synthesis may reflect trans- lational control mechanisms in the regulation of intestinal apo $B$ gene expression. This question is the focus of current investigation.

\section{Acknowledgments}

Excellent technical assistance was provided by M. E. Kollmer and K. Petro. The editorial assistance of Mrs. P. Cantwell is gratefully acknowledged. Dr. Davidson acknowledges with particular gratitude the support received from Dr. Robert M. Glickman, Columbia University, College of Physicians and Surgeons, New York. The generous assistance of Dr. P. Whitington, Department of Pediatric GI, University of Chicago, in the quantitation of total bile salt mass is also acknowledged. The authors acknowledge with gratitude the gift of rat fibronectin cDNA (Dr. R. Hynes, Massachusetts Institute of Technology, Boston, MA).

Dr. Davidson was supported by National Institutes of Health (NIH) grant HL 34461 and an American Gastroenterological Association/Smith Kline and French Industry Scholar Award. Dr. Elovson was supported by NIH grant HL 28481 and by the Veterans Administration.

\section{References}

1. Kane, J. P. 1983. Apolipoprotein B: Structural and metabolic heterogeneity. Annu. Rev. Physiol. 45:637-650.

2. Kane, J. P., D. A. Hardman, and H. E. Paulus. 1980. Heterogeneity of apolipoprotein B. Isolation of a new species from human chylomicrons. Proc. Natl. Acad. Sci. USA. 77:2465-2469.

3. Bell-Quint, J., T. Forte, and P. Graham. 1981. Synthesis of two forms of apolipoprotein B by cultured hepatocytes. Biochem. Biophys. Res. Commun. 99:700-706.

4. Davidson, N. O., M. E. Kollmer, and R. M. Glickman. 1986. Apolipoprotein B synthesis in rat small intestine. Regulation by dietary triglyceride and biliary lipid. J. Lipid Res. 27:30-39.

5. Swift, L. L., P. D. Soule, M. E. Gray, and V. S. LeQuire. 1984. Intestinal lipoprotein synthesis. Comparison of nascent golgi lipoproteins from chow-fed and hypercholesterolemic rats. J. Lipid Res. 25:1-13.

6. Yang, C.-Y., S.-H. Chen, S. H. Gianturco, W. A. Bradley, J. T. Sparrow, M. Tanimura, W.-H. Li, D. A. Sparrow, H. DeLoof, M. Rosseneu, F.-S. Lee, Z.-W. Gu, A. M. Gotto, Jr., and L. Chan. 1986. Sequence, structure, receptor-binding domains and internal repeats of human apolipoprotein B-100. Nature (Lond.). 323:738-742.

7. Law, S. W., K. J. Lackner, A. V. Hospattankar, J. M. Anchors, A. Y. Sakaguchi, S. L. Naylor, and H. B. Brewer, Jr. 1985. Human apolipoprotein B-100: Cloning, analysis of liver mRNA, and assignment of the gene to chromosome 2. Proc. Natl. Acad. Sci. USA. 82:8340-8344.

8. Cladaras, C., M. Hadzopoulou-Cladaras, R. T. Nolte, D. Atkinson, and V. I. Zannis. 1986. The complete sequence and structural analysis of human apolipoprotein B-100: Relationship between apo B-100 and apo B-48 forms. Eur. Mol. Biochem. Organ. J. 5:34953507.

9. Protter, A. A., D. A. Hardman, J. W. Schilling, J. Miller, V. Appleby, G. C. Chen, S. W. Kirsher, G. McEnroe, and J. P. Kane. 1986. Isolation of a cDNA clone encoding the amino-terminal region of human apolipoprotein B. Proc. Natl. Acad. Sci. USA. 83:14671471.

10. Knott, T. J., S. C. Rall, Jr., T. L. Innerarity, S. F. Jacobsen, M. S. Urdea, B. B. Levy-Wilson, L. M. Powell, R. J. Pease, R. Eddy, H. Nakai, M. Byers, L. M. Priestley, E. Robertson, L. B. Rall, C. Betsholtz, T. B. Shows, R. W. Mahley, and J. Scott. 1985. Human apolipoprotein B: structure of carboxyl-terminal domains, sites of gene expression, and chromosomal localization. Science (Wash. DC). 230:37-43.

11. Knott, T. J., R. J. Pease, L. M. Powell, S. C. Wallis, S. C. Rall, Jr., T. L. Innerarity, B. Blackhart, W. H. Taylor, Y. Marcel, R. Milne, 
D. Johnson, M. Fuller, A. J. Lusis, B. J. McCarthy, R. W. Mahley, B. Levy-Wilson, and J. Scott. 1986. Complete protein sequence and identification of structural domains of human apolipoprotein B. $\mathrm{Na}$ ture (Lond.). 323:734-738.

12. Lusis, A. J., R. West, M. Mehrabian, M. A. Reuben, R. C. LeBoeuf, J. S. Kaptein, D. F. Johnson, V. N. Schumaker, M. P. Yahasz, M. C. Schotz, and J. Elovson. 1985. Cloning and expression of apolipoprotein B, the major protein of low and very low density lipoproteins. Proc. Natl. Acad. Sci. USA. 82:4597-4601.

13. Powell, L. M., S. C. Wallis, R. J. Pease, Y. H. Edwards, T. J. Knott, and J. Scott. 1987. A novel form of tissue-specific RNA processing produces apolipoprotein B-48 in intestine. Cell. 50:831-840.

14. Chen, S.-H., G. Habib, C.-Y. Yang, Z.-W. Gu, B. R. Lee, S.-A. Weng, S. R. Silberman, S.-J. Cai, J. P. Deslypere, M. Rosseneu, A. M. Gotto, Jr., W.-H. Li and L. Chan. 1987. Apolipoprotein B-48 is the product of a messenger RNA with an organ-specific in-frame stop codon. Science (Wash. DC). 238:363-366.

15. Molloy, M. J., J. P. Kane, A. Hardman, R. L. Hamilton, and K. B. Dalal. 1981. Normotriglyceridemic abetalipoproteinemia. J. Clin. Invest. 67:1441-1450.

16. Herbert, P. N., J. S. Hyams, D. N. Bernier, M. M. Berman, A. L. Saritelli, K. M. Lynch, A. V. Nichols, and T. M. Forte. 1985. Apolipoprotein B-100 deficiency. Intestinal steatosis despite apolipoprotein B-48 synthesis. J. Clin. Invest. 76:403-412.

17. Bouma, M.-E., I. Beucler, L.-P. Aggerbeck, R. Infante, and J. Schmitz. 1986. Hypobetalipoproteinemia with accumulation of an apoprotein B-like protein in intestinal cells. J. Clin. Invest. 78:398410.

18. Glickman, R. M., M. Rogers, and J. N. Glickman. 1986. Apolipoprotein B synthesis by human liver and intestine in vitro. Proc. Natl. Acad. Sci. USA. 83:5296-5300.

19. Demmer, L. A., M. S. Levin, J. Elovson, M. A. Reuben, A. J. Lusis, and J. I. Gordon. 1986. Tissue-specific expression and developmental regulation of the rat apolipoprotein B gene. Proc. Natl. Acad. Sci. USA. 83:8102-8106.

20. Lowry, O. H., N. J. Rosebrough, A. L. Farr, and R. J. Randall. 1951. Protein measurement with the Folin phenol reagent. J. Biol. Chem. 193:265-275.

21. Gordon, J. I., D. P. Smith, R. Andy, D. H. Alpers, G. Schonfeld, and A. W. Strauss. 1982. The primary translation product of rat intestinal apolipoprotein A-I mRNA is an unusual preproprotein. $J$. Biol. Chem. 257:971-978.

22. Bailey, J. M., and N. Davidson. 1976. Methylmercury as a reversible denaturing agent for agarose gel electrophoresis. Anal. Biochem. 70:75-85.

23. Chirgwin, J. M., A. E. Przybyla, R. J. MacDonald, and W. J. Rutter. 1979. Isolation of biologically active ribonucleic acid from sources enriched in ribonuclease. Biochemistry. 18:5294-5299.

24. Feinberg, A. P., and B. Vogelstein. 1983. A technique for radiolabeling DNA restriction endonuclease fragments to high specific activity. Anal. Biochem. 132:6-13.

25. Thomas, P. S. 1980 . Hybridization of denatured RNA and small DNA fragments transferred to nitrocellulose. Proc. Natl. Acad. Sci. USA. 77:5201-5205.

26. Boguski, M. D., N. Elshourbagy, J. M. Taylor, and J. I. Gordon. 1984. Rat apolipoprotein AIV contains 13 tandem repetitions of a 22-amino acid segment with amphipathic helical potential. Proc. Natl. Acad. Sci. USA. 81:5021-5025.

27. Schwartzbauer, J. E., J. W. Tamkun, I. R. Lemischka, and R. O. Hynes. 1983. Three different fibronectin mRNAs arise by alternative splicing within the coding region. Cell. 35:421-431.

28. Mansbach, C. M., and S. Parthasarathy. 1982. A reexamination of the fate of glyceride-glycerol in neutral lipid absorption and transport. J. Lipid Res. 23:1009-1019.

29. Folch, J. L., M. Lees, and G. H. Sloane-Stanley. 1957. A simple method for the isolation and purification of total lipids from animal tissues. J. Biol. Chem. 226:497-509.

30. Brasitus, T. A., N. O. Davidson, and D. Schacter. 1985. Variations in dietary triacylglycerol saturation alter the lipid composition and fluidity of rat intestinal plasma membranes. Biochim. Biophys. Acta. 812:460-472.

31. Bartlett, G. R. 1959. Phosphorus assay in column chromatography. J. Biol. Chem. 234:466-468.

32. Gebhard, R. L., and W. F. Prigge. 1981. In vivo regulation of canine intestinal 3-hydroxy-3-methylglutaryl coenzyme A reductase by cholesterol, lipoprotein, and fatty acids. J. Lipid Res. 22:11111118.

33. Turley, S. D., and J. M. Dietschy. 1979. Regulation of biliary cholesterol output in the rat. Dissociation from the rate of hepatic cholesterl synthesis, the size of the hepatic cholesteryl ester pool, and the hepatic uptake of chylomicron cholesterol. J. Lipid Res. 20:923934.

34. Fausa, O. 1975. Quantitative determination of serum bile acids using a purified $3 \alpha$-hydroxysteroid dehydrogenase. Scand. J. Gastro. 10:747-752.

35. Davidson, N. O., and R. M. Glickman. 1985. Apolipoprotein A-I synthesis in rat small intestine. Regulation by dietary triglyceride and biliary lipid. J. Lipid Res. 26:368-379.

36. Davidson, N. O., A. M. Magun, T. A. Brasitus, and R. M. Glickman. 1987. Intestinal apo A-I and $B_{48}$ metabolism. Effects of sustained alterations in dietary triglyceride and mucosal cholesterol flux. J. Lipid Res. 28:388-402.

37. Nalbone, G., M. Charbonnier-Augier, H. Lafont, R. Grataroli, J.-L. Vigne, D. Lairon, C. Chabert, J. Leonardi, J. C. Hanton, and R. Verger. 1983. Adsorption of pancreatic (pro)phospholipase $A_{2}$ to various physiological substrates. J. Lipid Res. 24:1441-1450.

38. Armstrong, M. J., and M. C. Carey. 1982. The hydrophobic-hydrophilic balance of bile salts. Inverse correlation between reversephase high performance liquid chromatographic mobilities and micellar cholesterol-solubilizing capacities. J. Lipid Res. 23:70-80.

39. Nishizuka, Y. 1984. Turnover of inositol phospholipids and signal transduction. Science (Wash. DC). 225:1365-1370.

40. Berridge, M. J. 1984. Inositol triphosphate and diacylglycerol as second messenger. Biochem. J. 220:345-360.

41. Mansbach, C. M., A. Arnold, and M. A. Cox. 1985. Factors influencing triacylglycerol delivery into mesenteric lymph. Am. J. Physiol. 249:G642-648.

42. Mansbach, C. M., II, and A. Arnold. 1986. Steady-state kinetic analysis of triacylglycerol delivery into mesenteric lymph. Am. J. Physiol. 251:G263-G269.

43. Gangl, A., and R. K. Ockner. 1975. Intestinal metabolism of plasma free fatty acids. Intracellular compartmentation and mechanisms of control. J. Clin. Invest. 55:803-813.

44. Collins, J. J., and M. C. Phillips. 1982. The stability and structure of cholesterol-rich codispersions of cholesterol and phosphatidylcholine. J. Lipid Res. 23:291-298.

45. Rothblatt, G. H., L. Y. Argobast, and E. K. Ray. 1978. Stimulation of esterified cholesterol accumulation in tissue culture cells exposed to high density lipoproteins enriched in free cholesterol. J. Lipid Res. 19:350-358.

46. Mansbach, C. M., G. Pieroni, and R. Verger. 1982. Intestinal phospholipase, a novel enzyme. J. Clin. Invest. 69:368-376.

47. Walters, J. R. F., P. J. Horvath, and M. M. Weiser. 1986. Preparation of subcellular membranes from rat intestinal scrapings or isolated cells. Gastroenterology. 91:34-40.

48. Bell, R. M., and R. A. Coleman. 1980. Enzymes of glycerolipid synthesis in eukaryotes. Annu. Rev. Biochem. 49:459-487.

49. Parthasarathy, S., P. V. Subbiah, and J. Ganguly. 1974. The mechanism of intestinal absorption of phosphatidylcholine in rats. Biochem. J. 140:503-508.

50. Mansbach, C. M. 1977. The origin of chylomicron phosphatidylcholine in the rat. J. Clin. Invest. 60:411-420.

51. Mansbach, C. M., and S. Parthasarathy. 1979. Regulation of de novo phosphatidylcholine synthesis in rat intestine. J. Biol. Chem. 254:9688-9694.

52. Patton, G. M., S. Bennett-Clark, J. M. Fasulo, and S. J. Robbins. 1984. Utilization of individual lecithins in intestinal lipoprotein formation in the rat. J. Clin. Invest. 73:231-240. 